\title{
The folate status of reproductive-aged women in a randomised trial of a folate-fortified oral contraceptive: dietary and blood assessments
}

\author{
Paula M Castaño ${ }^{1, *}$, Aida Aydemir ${ }^{2}$, Carole Sampson-Landers ${ }^{2}$ and Richard Lynen ${ }^{2}$ \\ 'Department of Obstetrics and Gynecology, Columbia University Medical Center, 622 West 168th Street, \\ PH 16-69, New York, NY 10032, USA: ${ }^{2}$ Bayer HealthCare Pharmaceuticals Inc., Wayne, NJ, USA
}

Submitted 15 June 2012: Final revision received 4 February 2013: Accepted 20 February 2013: First published online 27 March 2013

\begin{abstract}
Objective: To assess the folate status of US women in a study of a folate-fortified oral contraceptive (OC) using the Short Folate Food Frequency Questionnaire and plasma and red blood cell (RBC) folate samples.

Design: Sub-analysis from a multi-centre, randomised, double-blind, controlled contraceptive trial with assessments at baseline and 6 months. We calculated dietary folate equivalents (DFE) consumed and the proportion of participants meeting folate adequacy benchmarks.

Setting: Eight centres in the USA.

Subjects: Healthy women aged 18-40 years requesting contraception with no contraindications for OC use.

Results: Overall, 385 participants were randomised to either a novel folatefortified OC or a marketed OC. The $262(68 \%)$ participants compliant with the protocol were included in the analysis set. Baseline daily DFE consumption was 529.8 (sD 342.1) $\mu \mathrm{g}$ and similar in both groups. At follow-up, the fortified OC group had higher intake than the conventional OC group (1225.9 (SD 346.2) $\mu \mathrm{g}$ compared with $500 \cdot 6(\mathrm{sD} 361 \cdot 2) \mu \mathrm{g}$ ). Mean plasma folate level increased from 44.5 (SD 17.2) to $55 \cdot 8$ (SD 21.1) nmol/l. Mean RBC folate level increased from 996.7 (sD 369.8) to 1311.9 (sD 436.0) $\mathrm{nmol} / \mathrm{l}$. The proportion meeting selected folate adequacy benchmarks increased in the fortified OC group $(P<0 \cdot 001)$. Conclusions: Lack of adequate folate intake in reproductive-aged women from dietary sources or supplements alone suggests the need for novel approaches. Use of folate-fortified OC ensures adequate folate levels and meeting of folate benchmarks.
\end{abstract}

\author{
Keywords \\ Dietary folate \\ Folate status \\ Folate-fortified oral contraceptive \\ Reproductive-aged women
}

The B vitamin, folate, and its synthetic form, folic acid, have a number of beneficial effects for both women of reproductive age and the general population. The most well-established benefit of folic acid supplementation is a reduction in the primary incidence ${ }^{(1)}$ and recurrence ${ }^{(2)}$ of neural tube defects (NTD). A dose-response relationship exists between red blood cell (RBC) folate level and NTD risk, with women having RBC folate level of $\geq 906 \mathrm{nmol} / 1$ having the lowest risk ${ }^{(3)}$. Possible reproductive benefits at birth include a decrease in the prevalence of severe congenital heart defects ${ }^{(4)}$, a reduction in the risk of cleft lip ${ }^{(5)}$ and a reduction in the incidence of preterm birth ${ }^{(6)}$. Folic acid may also reduce the risk of incident hypertension ${ }^{(7)}$, improve cognitive function ${ }^{(8)}$ and decrease depression scores in adults ${ }^{(9,10)}$. Few of these additional potential benefits have been conclusively established ${ }^{(11,12)}$. A potential risk is masking of vitamin $\mathrm{B}_{12}$ deficiency with long-term neurological sequelae ${ }^{(13)}$. Folic acid may protect against colorectal $^{(14,15)}$ and breast ${ }^{(12,16)}$ cancer, but a procarcinogenic effect is postulated in individuals with presence of neoplastic cells and high folate intake. Systematic reviews recommend ongoing surveillance and longer-term studies including high-dose intake ${ }^{(17,18)}$.

Since 1992, in an effort to decrease the incidence of NTD, the US Preventive Services Task Force has recommended a daily supplement of at least $400 \mu \mathrm{g}$ of folic acid for all women of reproductive age, commencing folic acid supplementation at least 1 month before conception and continuing with daily supplements through the first 2-3 months of pregnancy ${ }^{(19)}$. Furthermore, since 1998, the US Food and Drug Administration has mandated fortification of grain products, flour and pasta $(140 \mu \mathrm{g} / 100 \mathrm{~g}$ cereal product, in order to increase folic acid intake in the general population by $100 \mu \mathrm{g} / \mathrm{d})^{(20)}$. The American Congress of Obstetricians and Gynecologists also recommends folic acid supplementation for all women of reproductive age, 
particularly during the periconceptional period ${ }^{(21)}$, a time when many women may rely on oral contraception for pregnancy prevention. Similarly, the Healthy People 2010 Objective in place at the time the present study was conducted was that $80 \%$ of women of reproductive age consume $400 \mu \mathrm{g}$ of folic acid from fortified foods and supplements daily ${ }^{(22)}$; this was revised in the Healthy People 2020 Objective to a more attainable $26 \%{ }^{(23)}$. Additional objectives are that $33 \%$ take multivitamins or folic acid daily for a month prior to pregnancy and that only $22 \%$ have low RBC folate concentration $(<195 \mathrm{ng} / \mathrm{ml}$ or $441.9 \mathrm{nmol} / \mathrm{l})^{(23)}$. Despite these recommendations, national surveys indicate that, at most, only $40 \%$ of women of reproductive age take supplements containing folic acid on a daily basis ${ }^{(24)}$. Although nationwide blood folate levels have increased compared with pre-fortification levels, a substantial proportion of women of childbearing potential, including those consuming folate-fortified foods or taking folate supplements, have an RBC folate level below $906 \mathrm{nmol} / \mathrm{l}^{(25-29)}$, the level associated with the highest NTD protection ${ }^{(3)}$.

Folate intake can be assessed using dietary measures such as food recall diaries and $\mathrm{FFQ}^{(30)}$. Blood folate markers include plasma folate, a measure of recent intake, and RBC folate, which reflects long-term folate stores in the RBC. Correlations between FFQ and plasma folate levels in women range from $0 \cdot 186$ to $0 \cdot 63^{(12,31-38)}$, and from 0.00 to 0.28 between FFQ and RBC folate values $^{(34,35)}$. These FFQ request information on the consumption of eighty-four ${ }^{(32)}$ to $145^{(37)}$ food items for up to 1 year of recall ${ }^{(12,31,32)}$. Previous studies comparing FFQ with blood folate markers have not focused on women of reproductive age electing contraception.

Worldwide, women of reproductive age often choose oral contraceptives (OC) for pregnancy prevention between pregnancies ${ }^{(39,40)}$. Several circumstances, however, may lead to pregnancies that do not benefit from adequate preconceptional folic acid intake: (i) OC misuse $^{(41)}$; (ii) premature OC discontinuation with a switch to a less effective method ${ }^{(42,43)}$; (iii) rapid return to fertility after OC discontinuation ${ }^{(44)}$; and (iv) seeking pregnancy without a visit to a clinician ${ }^{(45)}$. Given the sustained RBC folate levels seen up to 5 months after discontinuation of a similar $\mathrm{OC}^{(46)}$, folate-containing OC could serve as a novel means of providing preconception folate should a pregnancy occur. As part of a study evaluating the effect of a novel OC fortified with folate on the change from baseline in plasma and RBC folate levels and homocysteine level ${ }^{(47)}$, we sought to assess the adequacy of folate status, using both dietary recall and blood folate markers, in a population of women in the USA - where food is fortified - desiring contraception. Furthermore, we investigated the relationship between folate intake measured using the Short Folate Food Frequency Questionnaire (SFFFQ) with blood folate levels.

\section{Methods}

\section{Study design and participants}

The current study was part of a multi-centre, randomised, double-blind, controlled contraceptive trial (ClinicalTrials.gov identifier: NCT00468481) that enrolled women from eight sites in the USA ${ }^{(47)}$. The trial was conducted in accordance with the International Conference on Harmonization/Good Clinical Practice and the principles stipulated by the Declaration of Helsinki. Each site obtained institutional review board approval, and written informed consent was obtained from all women prior to study entry. Study inclusion criteria included healthy women aged 18-40 years requesting contraception with no contraindications for OC use. The study population was designed to be representative of the US population; therefore, we included women of different ethnicities in rural and urban settings. We targeted a racially diverse study population in order to assess whether such differences lead to variations in folate-rich dietary choices. Study sites were divided into East (Maryland, North Carolina, South Carolina, Tennessee and New York) and West (Washington and California). During screening, study site personnel recorded subject-reported racial/ethnic groups from the categories: Caucasian, African American, Hispanic, Asian and Other.

Participants received either: (i) an OC containing $20 \mu \mathrm{g}$ ethinylestradiol and $3 \mathrm{mg}$ drospirenone for $24 \mathrm{~d}$ followed by $4 \mathrm{~d}$ of placebo $\left(\mathrm{YAZ}^{\circledR}\right.$; Bayer HealthCare Pharmaceuticals, Berlin, Germany) and served as controls; or (ii) the same OC fortified with $451 \mu \mathrm{g}$ levomefolate calcium (Metafolin ${ }^{\circledR}$ ) (BEYAZ ${ }^{\circledR}$; Bayer HealthCare Pharmaceuticals) for $28 \mathrm{~d}$ and represented the intervention group (folate-fortified OC). Unlike folic acid, levomefolate calcium does not need to be metabolised to be biologically active and is, therefore, independent of folate-converting enzymes which control the activation of folic acid. Furthermore, levomefolate calcium has less potential than folic acid to mask vitamin $\mathrm{B}_{12}$ deficiency symptoms ${ }^{(48)}$. At equimolar doses, levomefolate calcium and folic acid ( $451 \mu \mathrm{g}$ levomefolate calcium is equivalent to $400 \mu \mathrm{g}$ folic acid) have also been shown to be similarly effective at increasing plasma and RBC folate levels in women of childbearing potential ${ }^{(49-51)}$. To ensure blinding, both medications had identical packaging. Randomisation was allocated in a 3:1 ratio (fortified OC:control) and study sites received treatment group assignment via an interactive voice response system.

Participants underwent the following visits: two screening visits, a baseline visit, six study visits over the course of 24 weeks, and a final visit at 26-28 weeks. We assessed dietary intake at the baseline and final visits for participants using the SFFFQ. Plasma and RBC folate samples were collected at the pretreatment and week 24 visits. The per protocol (PP) participants reported at least $75 \%$ study medication compliance per cycle, had no 
major protocol deviations and completed 24 weeks of treatment.

\section{The Short Folate Food Frequency Questionnaire}

The SFFFQ (C) Columbia University 2007) is similar in design to widely used $\mathrm{FFQ}^{(52)}$. However, it assesses only folate-rich foods consumed in the last week and, therefore, contains fewer items and takes less time to complete $^{(53)}$. It was developed to serve as a rapid selfadministered assessment of dietary folate status in dietary folate equivalents (DFE), units that account for the differences in bioavailability of natural food folate and synthetic folic acid ${ }^{(13)}$. The SFFFQ is used to collect information about vitamin and supplement intake and the number of servings of multiple preparations of thirty-nine folate-containing foods consumed in the past week. Where available, we obtained $\mu \mathrm{g}$ of DFE for food preparations from the US Department of Agriculture's National Nutrient Database for Standard Reference ${ }^{(54)}$; for others, we utilised product labelling or contacted the manufacturer. For fortified foods, we did not record separately the individual contribution to total $\mu \mathrm{g}$ of DFE from natural food folate and synthetic folic acid. For vitamins and supplements, we multiplied standard values of folic acid in $\mu \mathrm{g}$ ( $400 \mu \mathrm{g}$ and $800 \mu \mathrm{g}$, respectively) by $1 \cdot 7$ to obtain $\mu \mathrm{g}$ of DFE. For individuals who specified other supplements that contain folic acid, we obtained folic acid values from product labelling prior to multiplying by the conversion factor. For the fortified OC, we calculated $\mu \mathrm{g}$ of DFE by multiplying $400 \mu \mathrm{g}$ by week 24 compliance and by the folate conversion factor. We then calculated daily consumption for diet plus vitamins/ supplements plus the contribution from the fortified OC. We assigned participants consuming at least $320 \mu \mathrm{g}$ DFE/d to meeting the Estimated Average Requirement (EAR), a dietary reference intake measure of adequate dietary intake for a group ${ }^{(13)}$. As we did not collect separately the folic acid contribution (in $\mu \mathrm{g}$ ) in fortified foods, we were unable to calculate the Healthy People 2020 Objective regarding ideal intake of folic acid ${ }^{(23)}$.

Only $0.35 \%$ of SFFFQ items had an unspecified number of servings or were missing brand names. We imputed $27 \%$ of the missing values based on individual intake from another visit with comparable intake and the remaining $73 \%$ from the median for all participants who consumed that item if no comparable visit data were available.

\section{Blood assessments}

We obtained all blood samples after a reported $12 \mathrm{~h}$ period of fasting. Baseline values reflect the mean of the three pretreatment values. Samples for RBC and plasma folate were drawn in separate lithium-heparin coated tubes. RBC folate samples were prepared by dilution with fresh $1 \% \mathrm{w} / \mathrm{v}$ ascorbic acid solution, followed by centrifugation and incubation in the dark for $30 \mathrm{~min}$ before storing at $-80^{\circ} \mathrm{C}$. Plasma folate samples were centrifuged and stored at $-80^{\circ} \mathrm{C}$. Specimens were shipped to the reference laboratory, TNO Quality of Life, The Netherlands, for analysis. Plasma and whole-blood folate concentrations were determined using a validated microbiological assay. Each plate included a WHO folate standard control. RBC folate concentrations were calculated using the equation $^{(47)}$ : $\{($ whole blood folate $\times 100)-$ [plasma folate $\times(100$ - haematocrit $)]\} /$ haematocrit.

We assigned participants with RBC folate level of $\geq 906 \mathrm{nmol} / 1$ to having optimal folate status for NTD protection $^{(3)}$. Similarly, participants with RBC folate $>441.9 \mathrm{nmol} / 1$ met the Healthy People 2020 Objective regarding low RBC folate concentration ${ }^{(23)}$.

\section{Statistical analysis}

We performed univariate analyses of demographic and dietary and blood folate data, bivariate analyses (Student's $t$ test for comparison of means and Pearson's $\chi^{2}$ test for comparison of proportions) to determine associations, paired $t$ tests to determine differences across visits, and calculated Pearson correlation coefficients to compare dietary and blood folate values. We performed the analyses using the statistical software packages SPSS version 18.0 for Windows and SAS version $9 \cdot 1$ for Windows.

\section{Results}

Participants were enrolled from 30 April 2007 to 6 September 2008. Overall, 385 participants were randomised, of whom 379 (98\%) received the intervention (either the OC or the folate-fortified OC), 273 (71\%) completed the study and 262 (68\%) completed the study per protocol (Fig. 1). PP participants reported $100 \%$ OC compliance at week 24 (range 89-104\%). One participant at baseline and four participants at the week 24 visit did not complete the SFFFQ. Due to a sample processing error at two clinical sites, valid RBC folate values were not attainable for all participants; valid RBC folate samples were balanced across treatment groups. RBC folate values were obtained for 196 (75\%) participants at baseline and 185 (71\%) at the final visit; 169 (62\%) participants had RBC folate values at both visits. We obtained plasma folate values for all participants at both time points.

Demographic and baseline participant characteristics are outlined in Table 1. PP participants did not differ from the group excluded from analyses in mean age, region or BMI. Dietary and blood folate values were also similar. There were racial/ethnic differences, however, with fewer PP participants identifying as African American (9\% v. 18\%) and more as Hispanic (14\% v. 9\%) and Asian (10\% v. 4\%; $P=0 \cdot 03)$.

\section{Dietary folate equivalents}

We calculated daily $\mu \mathrm{g}$ of DFE consumption by visit (Table 2). At baseline, 159 (61\%) participants reported 


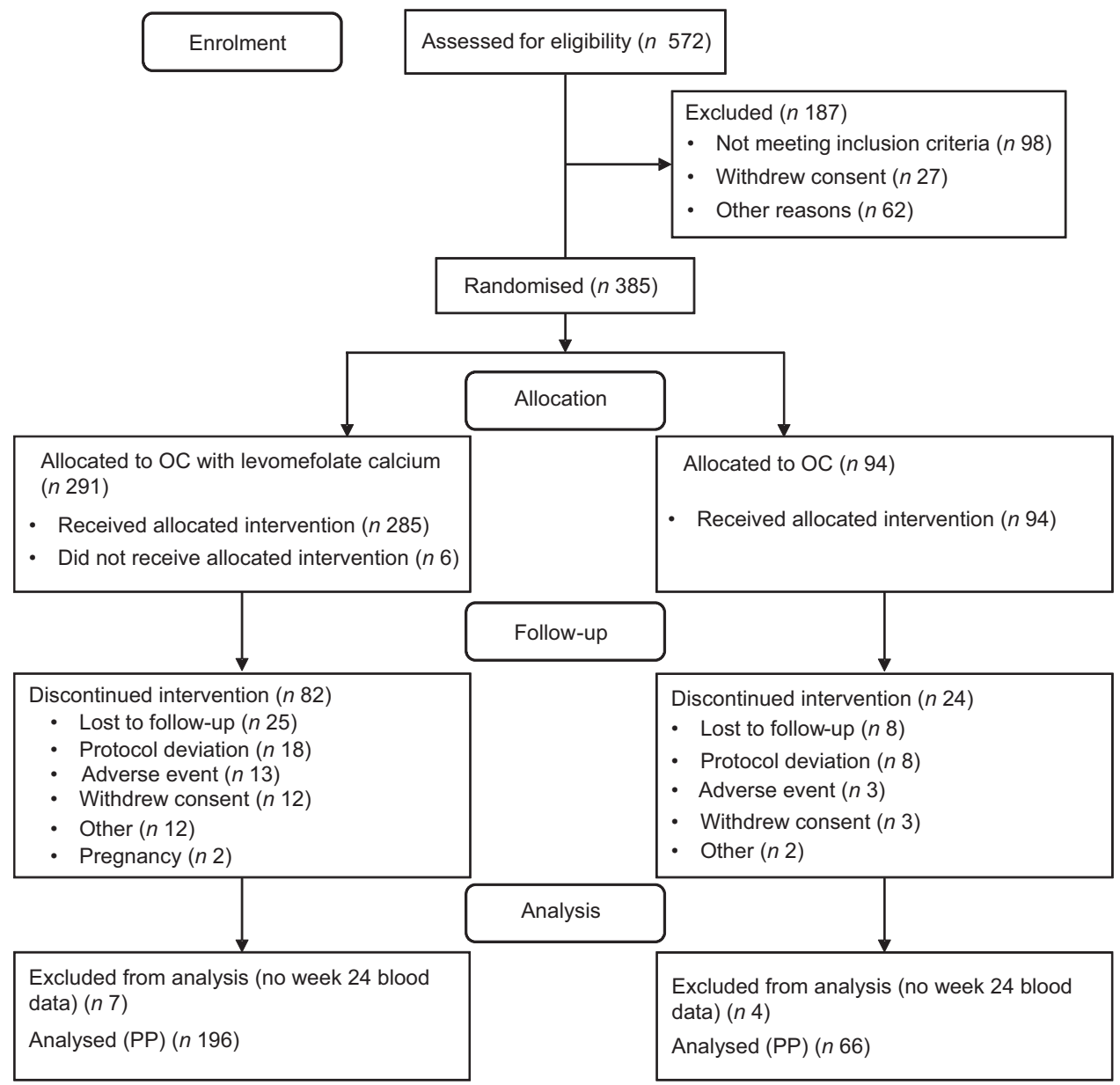

Fig. 1 Participant flow through the study (OC, oral contraceptive; PP, per protocol)

Table 1 Demographic and baseline characteristics (per protocol set; $n$ 262): healthy women of reproductive age enrolled in a randomised trial of a folate-fortified oral contraceptive, eight centres in the USA, 2007-2009

\begin{tabular}{|c|c|c|}
\hline & Mean & SD \\
\hline \multirow[t]{2}{*}{ Age (years) } & 25 & $4 \cdot 9$ \\
\hline & $n$ & $\%$ \\
\hline \multicolumn{3}{|l|}{ Age (years) } \\
\hline $18-19$ & 33 & 13 \\
\hline 20-35 & 217 & 83 \\
\hline$>35$ & 12 & 5 \\
\hline \multicolumn{3}{|l|}{ Race/ethnicity } \\
\hline Caucasian & 166 & 63 \\
\hline African American & 24 & 9 \\
\hline Hispanic & 37 & 14 \\
\hline Asian & 25 & 10 \\
\hline Other & 10 & 4 \\
\hline \multicolumn{3}{|l|}{ Region } \\
\hline East (Maryland, North Carolina, South Carolina, Tennessee and New York) & 146 & 56 \\
\hline West (Washington and California) & 116 & 44 \\
\hline \multicolumn{3}{|l|}{ Randomisation } \\
\hline Intervention & 196 & 75 \\
\hline Control & 66 & 25 \\
\hline \multicolumn{3}{|l|}{ BMl category $\left(\mathrm{kg} / \mathrm{m}^{2}\right)$} \\
\hline Underweight $(<18 \cdot 5)$ & 10 & 4 \\
\hline Normal $(18 \cdot 5-24 \cdot 9)$ & 158 & 60 \\
\hline Overweight $(25.0-29.9)$ & 75 & 29 \\
\hline Obese $(\geq 30 \cdot 0)$ & 19 & 7 \\
\hline
\end{tabular}


Table 2 Mean daily folate intakes (in $\mu \mathrm{g}$ of dietary folate equivalents) by study visit: healthy women of reproductive age enrolled in a randomised trial of a folate-fortified oral contraceptive, eight centres in the USA, 2007-2009

\begin{tabular}{|c|c|c|c|c|c|c|}
\hline & \multicolumn{3}{|c|}{ Baseline } & \multicolumn{3}{|c|}{ Week 24} \\
\hline & $n$ & Mean & SD & $n$ & Mean & SD \\
\hline \multicolumn{7}{|c|}{ Diet plus supplements } \\
\hline Control & 66 & $511 \cdot 3$ & $341 \cdot 6$ & 66 & $500 \cdot 6$ & $361 \cdot 2$ \\
\hline Fortified OC & 195 & $537 \cdot 6$ & $343 \cdot 0$ & 192 & $546 \cdot 7$ & $346 \cdot 0$ \\
\hline All & 261 & $529 \cdot 8$ & $342 \cdot 1$ & 258 & 534.9 & $349 \cdot 8$ \\
\hline \multicolumn{7}{|c|}{ Diet plus supplements plus $O C$ contribution } \\
\hline Control & & & & 66 & $500 \cdot 6$ & $361 \cdot 2$ \\
\hline Fortified OC & & & & 192 & $1225 \cdot 9^{*}$ & $346 \cdot 2$ \\
\hline All & & & & 258 & $1040 \cdot 3^{\star}$ & $471 \cdot 8$ \\
\hline
\end{tabular}

OC, oral contraceptive.

Mean values were significantly different from those at baseline: ${ }^{\star} P<0.001$

ready-to-eat cereal consumption and their folic acid intake from this dietary component was $225 \cdot 7$ (SD 190.9) $\mu \mathrm{g}$ DFE/d. Only 67 (26\%) reported vitamin or supplement intake and their folic acid intake from supplements was $421 \cdot 2$ (SD 239.8) $\mu \mathrm{g}$ DFE/d. The total DFE intake at baseline was $529 \cdot 8$ (SD 342.1) $\mu \mathrm{g} / \mathrm{d}$.

Participants were similar at follow-up for ready-to-eat cereal consumption ( $n$ 156, 60\%) and vitamin/supplement intake ( $n$ 63, 24\%). The total DFE intake was 534.9 (SD 349.8) $\mu \mathrm{g} / \mathrm{d}$ but increased to $1040 \cdot 3$ (SD 471.8) $\mu \mathrm{g} / \mathrm{d}$ when the contribution from the fortified OC was included.

Dietary intake of folate did not differ between the groups at baseline $(P=0 \cdot 6)$ and at week $24(P=0 \cdot 4)$ or within the groups between these points in time (controls: $P=0 \cdot 8$, fortified OC: $P=0 \cdot 7)$. There was no difference between mean $\mu \mathrm{g}$ of $\mathrm{DFE} / \mathrm{d}$ at the baseline visit and final visit by folate consumption category (data not shown). Furthermore, there were no differences in the change in total intake mean $\mu \mathrm{g}$ of DFE/d from baseline to follow-up by age category, race/ethnicity, geographic region, study group assignment and BMI category (data not shown).

The folate intake categories that contributed the most DFE to the total consumption at baseline and follow-up were ready-to-eat cereals (26\% and $25 \%$, respectively) and vitamins/supplements (20\% and 23\%, respectively). Breads (mostly white), pasta, rice, beans (mostly pinto) and romaine lettuce were the five next most common contributors to dietary folate at both visits (all <9\%).

\section{Blood folate levels}

Plasma folate values increased during the study for the combined study population $(P<0 \cdot 001$; Table 3$)$; this increase was due to the increase in the fortified OC group. There was no increase in the mean plasma folate values in the control group but there was an increase in the intervention group $(P<0 \cdot 001)$. Similarly, RBC folate values increased during the study in the two groups combined $(P<0 \cdot 001)$; again, this increase was due to the fortified OC group $(P<0 \cdot 001)$. No increase in RBC folate was observed in the control group.
Table 3 Mean blood folate levels ( $\mathrm{nmol} / \mathrm{l})$ by study visit: healthy women of reproductive age enrolled in a randomised trial of a folate-fortified oral contraceptive, eight centres in the USA, 2007-2009

\begin{tabular}{|c|c|c|c|c|c|c|}
\hline & \multicolumn{3}{|c|}{ Baseline } & \multicolumn{3}{|c|}{ Week 24} \\
\hline & $n$ & Mean & SD & $n$ & Mean & SD \\
\hline \multicolumn{7}{|l|}{ Plasma folate } \\
\hline Control & 66 & $43 \cdot 1$ & $16 \cdot 1$ & 66 & $41 \cdot 0$ & $17 \cdot 6$ \\
\hline Fortified OC & 196 & $45 \cdot 0$ & $17 \cdot 6$ & 196 & $60 \cdot 8^{*}$ & $19 \cdot 9$ \\
\hline All & 262 & $44 \cdot 5$ & $17 \cdot 2$ & 262 & $55 \cdot 8^{*}$ & $21 \cdot 1$ \\
\hline \multicolumn{7}{|l|}{ RBC folate } \\
\hline Control & 52 & $1014 \cdot 3$ & $308 \cdot 2$ & 47 & $1027 \cdot 2$ & $292 \cdot 3$ \\
\hline Fortified OC & 144 & $990 \cdot 4$ & $390 \cdot 4$ & 138 & $1408 \cdot 9^{*}$ & $435 \cdot 2$ \\
\hline All & 196 & $996 \cdot 7$ & $369 \cdot 8$ & 185 & $1311 \cdot 9^{*}$ & $436 \cdot 0$ \\
\hline
\end{tabular}

OC, oral contraceptive; RBC, red blood cell.

Mean values were significantly different from those at baseline: ${ }^{\star} P<0.001$.

Subgroup analyses revealed no difference in both mean plasma and RBC folate levels over the course of the study in women aged over 35 years and for race/ethnicity 'Other'. Since these subgroups were small (twelve and ten individuals, respectively), this may be a chance occurrence. Similarly, mean plasma folate did not increase over time in the ten women who were underweight.

\section{Folate benchmarks}

The percentage meeting or exceeding the EAR $(320 \mu \mathrm{g}$ of $\mathrm{DFE} / \mathrm{d}$ ) in this population was $66 \%$ at baseline (Table 4 ). Meeting the EAR did not differ by any of the demographic variables assessed. Meeting the EAR increased to $90 \%$ at follow-up $(P<0 \cdot 001)$. This was due to the increase in the fortified OC group. Participants meeting the EAR at follow-up tended to be older $(P=0 \cdot 02)$. There were no other differences in meeting the EAR at follow-up by any of the demographic variables.

At baseline, only $55 \%$ of participants met or exceeded $906 \mathrm{nmol} / \mathrm{l}$, the value of RBC folate associated with maximum NTD risk reduction. After 24 weeks, however, $83 \%$ overall (91\% in the fortified OC group and 60\% in the control group) met this value $(P<0 \cdot 001)$. We found low RBC folate in two participants at baseline and one at follow-up. 
Table 4 Participants meeting folate benchmarks by study visit: healthy women of reproductive age enrolled in a randomised trial of a folate-fortified oral contraceptive, eight centres in the USA, 2007-2009

\begin{tabular}{|c|c|c|c|c|c|c|}
\hline & \multicolumn{3}{|c|}{ Baseline } & \multicolumn{3}{|c|}{ Week 24} \\
\hline & $N$ & $n$ & $\%$ & $N$ & $\mathrm{n}$ & $\%$ \\
\hline \multicolumn{7}{|l|}{ EAR } \\
\hline Control & 66 & 42 & 64 & 66 & 40 & 61 \\
\hline Fortified OC & 195 & 131 & 67 & 192 & $192^{*}$ & 100 \\
\hline All & 261 & 173 & 66 & 258 & $232^{*}$ & 90 \\
\hline \multicolumn{7}{|l|}{ NTD protection } \\
\hline Control & 52 & 34 & 66 & 47 & 28 & 60 \\
\hline Fortified OC & 144 & 74 & 51 & 138 & $126^{\star}$ & 91 \\
\hline All & 196 & 108 & 55 & 185 & $154^{*}$ & 83 \\
\hline \multicolumn{7}{|c|}{ Healthy People 2020 Objective 15} \\
\hline Control & 52 & 52 & 100 & 47 & 47 & 100 \\
\hline Fortified OC & 144 & 142 & 99 & 138 & 137 & 99 \\
\hline All & 196 & 194 & 99 & 185 & 184 & 100 \\
\hline
\end{tabular}

$N$, total number of participants in the group; $n$, number of participants in the group meeting the benchmark; EAR, Estimated Average Requirement $=320$ $\mu \mathrm{g}$ of dietary folate equivalents/d; OC, oral contraceptive; NTD protection, participants meeting maximum neural tube defect protection threshold of RBC folate $\geq 906 \mathrm{nmol} / \mathrm{l}$; Healthy People 2020 Maternal, Infant, and Child Health Objective $15=$ participants with RBC folate $>195 \mathrm{ng} / \mathrm{ml}(441.9 \mathrm{nmol} / \mathrm{l})$. Significantly different from baseline: ${ }^{\star} P<0.001$.

Table 5 Correlations between blood folate levels and dietary folate as assessed via the SFFFQ by study visit: healthy women of reproductive age enrolled in a randomised trial of a folate-fortified oral contraceptive, eight centres in the USA, 2007-2009

\begin{tabular}{lccccc}
\hline & \multicolumn{2}{c}{ Baseline } & & \multicolumn{2}{c}{ Week 24 } \\
\cline { 2 - 3 } \cline { 6 - 6 } & $n$ & & & $n$ & $r$ \\
\hline Plasma folate & 261 & 0.34 & & 258 & 0.43 \\
RBC folate & 196 & 0.35 & & 184 & 0.41 \\
\hline
\end{tabular}

SFFFQ, Short Folate Food Frequency Questionnaire; $r$, Pearson correlation coefficient; RBC, red blood cell.

All correlations were significant at $P<0.05, \rho \neq 0$.

\section{Correlations}

Total dietary intake in $\mu \mathrm{g}$ of $\mathrm{DFE} / \mathrm{d}$ correlated with both plasma and RBC folate at baseline $(r=0.34$ and $r=0.35$, respectively) and remained correlated at follow-up $(r=0 \cdot 43$ and $r=0 \cdot 41$, respectively; Table 5). When evaluating demographic variables for week 24 (data not shown), correlation of dietary intake measured by the SFFFQ with plasma folate was highest in those women who were of a younger age $(r=0.47)$, lived in the West $(r=0.53)$ and had a normal BMI $(r=0 \cdot 48)$. For RBC folate, the highest correlation was in women who were older $(r=0.52)$, Caucasian $(r=0.43)$ and overweight and obese $(r=0.52$ and $r=0.43$, respectively). There was more variability in correlations at the final visit than at baseline (Fig. 2).

\section{Discussion}

In a racially and geographically diverse group of US women exposed to fortified foods who elected to use oral contraception, mean daily dietary intake of folate calculated from the SFFFQ in DFE remained stable over the 6-month study period. Dietary folate levels increased in the group assigned to an OC fortified with levomefolate calcium. Similarly, while plasma and RBC folate levels remained stable in the control group, those in the fortified OC group had an increase in these short- and long-term blood folate stores. These increases improved performance of this population on two folate benchmarks we assessed: meeting the EAR and the NTD protection threshold.

The current study enrolled only women of reproductive age, the age group that stands to benefit the most from adequate folate stores. This is also the age group that often selects an OC as their form of contraception ${ }^{(39)}$. Unfortunately, OC discontinuation is high ${ }^{(55-57)}$, often occurs without consulting a physician ${ }^{(45)}$ and leaves women at risk for an unintended pregnancy. Therefore, attaining adequate folate stores in this population is very important. The percentage of participants meeting the EAR measure of group folate intake adequacy was low (66\%) when assessed using the SFFFQ at baseline, but $100 \%$ in the folate-fortified group at 6 months. The percentage not meeting the EAR at baseline was higher than in an analysis of data from the National Health and Nutrition Examination Survey ${ }^{(58)}$. This may reflect differences in methodology of dietary assessment between these two studies.

We demonstrated that fortified OC use in a food-fortified population increased the proportion of participants with RBC folate $\geq 906 \mathrm{nmol} / 1$ from half $(51 \%)$ to almost all (91\%), thus decreasing their risk of a pregnancy affected by an NTD. Folate stores above baseline would be expected to persist for several months after OC discontinuation ${ }^{(46)}$. A woman discontinuing such an OC and becoming pregnant within a few months would likely receive the protective reproductive benefits of folate use. A folate-fortified OC could thus serve as a proxy for a daily folic acid supplement and help a woman meet the Healthy People 2020 Objective of daily supplement for a month prior to pregnancy ${ }^{(23)}$.

This population met the Healthy People 2020 Objective for reducing the proportion of women with low RBC folate concentrations at baseline ${ }^{(23)}$. The high RBC folate concentration in our population at both time points may reflect the effect of fortification and supplement intake.

While we did not intend to validate the folate-specific SFFFQ in our study, it performed well in this population. It correlated with plasma and RBC folate levels as well as, if not better than, other FFQ in the existing literature with fewer items and shorter recall requirement. The correlation between the dietary assessment and blood values was positive and highest in the fortified OC group.

The study had some limitations. The SFFFQ relies on self-reported consumption of selected folate-rich foods and assumes unbiased reporting of intake. We collected a single SFFFQ at each time point and thus could not adjust for within-person variability. The SFFFQ collects a week's 

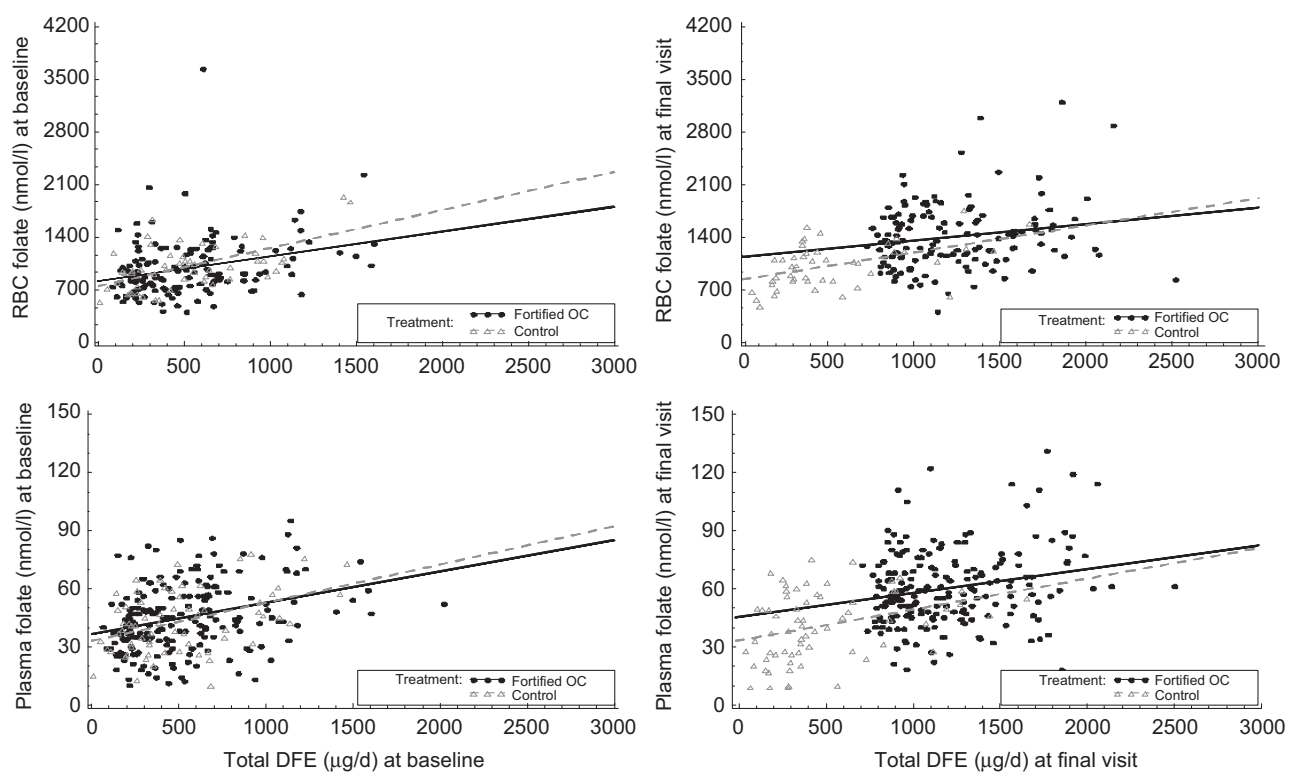

Fig. 2 Correlations between red blood cell (RBC) folate, plasma folate and total dietary folate equivalents (DFE) at baseline and final visit: healthy women of reproductive age enrolled in a randomised trial of a folate-fortified oral contraceptive, eight centres in the USA, 2007-2009

worth of intake data, however, and dietary intake remained stable throughout the study period. We relied on a national database and, infrequently, product labels for $\mu \mathrm{g}$ of DFE. Databases and product labels can underestimate real folate values because of limitation of analytical methods ${ }^{(13,59)}$ and product labels are not regulated; however, neither of these should have differed by group assignment. In converting to $\mu \mathrm{g}$ of DFE, we assumed fortificants/supplements were consumed with food and not fasting ( 1.7 conversion factor). This could be an underestimate if supplementary folate was consumed while fasting ( $2 \cdot 0$ conversion factor).

Our data set included only total folate intake in DFE. For fortified foods it did not collect separately the folic acid and natural food folate contributions. Our food folate benchmark calculations were thus limited to the EAR and we were unable to directly calculate the Healthy People 2020 Objective 14 of $26 \%$ with an intake of at least $400 \mu \mathrm{g}$ of folic acid/d from fortified foods or supplements. Given that $26 \%$ of the study population reported supplement use at baseline, we can infer that this population likely met this benchmark. Lastly, our results may not be generalisable to countries with different (or no) food fortification or with food consumption that is not captured by the SFFFQ.

The strengths of the study include a geographically and demographically diverse study population of US women of reproductive age. Further strengths are that, as would be expected for diet, reported folate consumption, excluding the fortified OC, was stable during the course of the study. Furthermore, based on diet alone, meeting the EAR did not differ from the beginning to the end of the study. Dietary findings are strengthened by correlation with blood values.
These results underscore the importance of food fortification for achieving adequate DFE. Fortified foods contributed the most to dietary intake; vitamins also contributed a large proportion of DFE. However, neither diet, including fortified foods, nor routine supplement intake alone was sufficient for all women to meet the EAR despite nationwide attempts to increase awareness and intake of folate. Worldwide, folic acid health campaigns have similarly increased knowledge and awareness with moderate increases in consumption ${ }^{(60)}$. Ongoing lack of adequate folate intake from dietary sources or supplements alone suggests the need for novel ways of providing supplementation to ensure adequate folate levels. The folate-containing OC tested here provides an example of supplementation targeted at a population (women of reproductive age) that does not always have adequate levels with their current diet and supplementation, and which is the intended beneficiary of improvement in folate status. Furthermore, the SFFFQ performed well in this study population and should be considered when a rapid assessment of dietary folate status is needed.

\section{Acknowledgements}

Sources of funding: The study was funded by Bayer HealthCare Pharmaceuticals, Berlin, Germany, the manufacturer of $\mathrm{YAZ}^{\circledR}$ and BEYAZ ${ }^{\circledR}$ (the folate-fortified OC). Ethics: The approving ethics committee was Independent Investigational Review Board, Plantation, FL, USA. Conflicts of interest: C.S.-L. and R.L. are employees of Bayer HealthCare Pharmaceuticals Inc. A.A. was an employee of Bayer 
HealthCare Pharmaceuticals Inc. during the study. P.M.C. has received payments for serving as a scientific advisor for Bayer HealthCare Pharmaceuticals Inc. and as a clinical investigator for Bayer Schering Pharma AG; she also serves as a preceptor for Conceptus and Merck. Authors' contributions: All authors made substantial contributions to the concept and design or analysis and interpretation of data, and to the drafting of the manuscript or revising it critically for important intellectual content. C.S.-L., A.A. and R.L. contributed to the data review/analysis, data interpretation and review/revision of the manuscript. P.M.C. contributed to the data analysis and interpretation, and drafted and revised the manuscript. In addition, all authors provided final approval of the manuscript. Acknowledgements: The authors would like to thank Amy Evans of inScience Communications, Springer Healthcare, for undertaking an edit of the manuscript.

\section{References}

1. Czeizel AE \& Dudas I (1992) Prevention of the first occurrence of neural-tube defects by periconceptional vitamin supplementation. $N$ Engl J Med 327, 1832-1835.

2. MRC Vitamin Study Research Group (1991) Prevention of neural tube defects: results of the Medical Research Council Vitamin Study. Lancet 338, 131-137.

3. Daly LE, Kirke PN, Molloy A et al. (1995) Folate levels and neural tube defects. Implications for prevention. JAMA 274, 1698-1702.

4. Ionescu-Ittu R, Marelli AJ, Mackie AS et al. (2009) Prevalence of severe congenital heart disease after folic acid fortification of grain products: time trend analysis in Quebec, Canada. BMJ 338, b1673.

5. Wilcox AJ, Lie RT, Solvoll K et al. (2007) Folic acid supplements and risk of facial clefts: national population based case-control study. BMJ 334, 464.

6. Bukowski R, Malone FD, Porter FT et al. (2009) Preconceptional folate supplementation and the risk of spontaneous preterm birth: a cohort study. PLoS Med 6, e1000061.

7. Forman JP, Rimm EB, Stampfer MJ et al. (2005) Folate intake and the risk of incident hypertension among US women. JAMA 293, 320-329.

8. Durga J, van Boxtel MP, Schouten EG et al. (2007) Effect of 3 -year folic acid supplementation on cognitive function in older adults in the FACIT trial: a randomised, double blind, controlled trial. Lancet 369, 208-216.

9. Taylor MJ, Carney S, Geddes J et al. (2003) Folate for depressive disorders. Cochrane Database Syst Rev issue 2, CD003390.

10. Taylor MJ, Carney SM, Goodwin GM et al. (2004) Folate for depressive disorders: systematic review and meta-analysis of randomized controlled trials. J Psychopharmacol 18, 251-256.

11. Malouf R \& Grimley Evans J (2008) Folic acid with or without vitamin $\mathrm{B}_{12}$ for the prevention and treatment of healthy elderly and demented people. Cochrane Database Syst Rev issue 4, CD004514.

12. Zhang SM, Willett WC, Selhub J et al. (2003) Plasma folate, vitamin $\mathrm{B}_{6}$, vitamin $\mathrm{B}_{12}$, homocysteine, and risk of breast cancer. J Natl Cancer Inst 95, 373-380.

13. Institute of Medicine Standing Committee on the Scientific Evaluation of Dietary Reference Intakes (1998) Dietary Reference Intakes for Thiamin, Riboflavin, Niacin, Vitamin $B_{6}$, Folate, Vitamin $B_{12}$, Pantothenic Acid, Biotin, and Choline. Washington, DC: National Academy Press.
14. Kennedy DA, Stern SJ, Moretti M et al. (2011) Folate intake and the risk of colorectal cancer: a systematic review and meta-analysis. Cancer Epidemiol 35, 2-10.

15. Stevens VL, McCullough ML, Sun J et al. (2011) High levels of folate from supplements and fortification are not associated with increased risk of colorectal cancer. Gastroenterology 141, 98-105.

16. Zhang SM, Cook NR, Albert CM et al. (2008) Effect of combined folic acid, vitamin $\mathrm{B}_{6}$, and vitamin $\mathrm{B}_{12}$ on cancer risk in women: a randomized trial. JAMA 300, 2012-2021.

17. Baggott JE, Oster RA \& Tamura T (2012) Meta-analysis of cancer risk in folic acid supplementation trials. Cancer Epidemiol 36, 78-81.

18. Mason JB (2011) Unraveling the complex relationship between folate and cancer risk. BioFactors 37, 253-260.

19. US Preventive Services Task Force (2009) Folic acid for the prevention of neural tube defects: US Preventive Services Task Force Recommendation Statement. Ann Intern Med 150, 626-631.

20. Food and Drug Administration (1996) Food labeling: health claims and label statements; folate and neural tube defects. Fed Reg 61, 8752-8781.

21. ACOG Committee on Practice Bulletins (2003) ACOG practice bulletin. Clinical management guidelines for obstetrician-gynecologists. Neural tube defects. Number 44, July 2003. Obstet Gynecol 102, 203-213.

22. US Department of Health and Human Services (2010) Healthy People 2010. http://www.healthypeople.gov/2010/document/ $\mathrm{html} /$ objectives/16-16.htm (accessed December 2010).

23. US Department of Health and Human Services (2010) Healthy People 2020. http://healthypeople.gov/2020/topics objectives2020/objectiveslist.aspx?topicId $=26 \quad$ (accessed May 2011).

24. Centers for Disease Control and Prevention (2008) Use of supplements containing folic acid among women of childbearing age - United States, 2007. MMWR Morb Mortal Wkly Rep 57, 5-8.

25. Brown JE, Jacobs DR Jr, Hartman TJ et al. (1997) Predictors of red cell folate level in women attempting pregnancy. JAMA 277, 548-552.

26. Caudill MA, Le T, Moonie SA et al. (2001) Folate status in women of childbearing age residing in Southern California after folic acid fortification. J Am Coll Nutr 20, 129-134.

27. Dietrich M, Brown CJ \& Block G (2005) The effect of folate fortification of cereal-grain products on blood folate status, dietary folate intake, and dietary folate sources among adult non-supplement users in the United States. $\mathrm{J} \mathrm{Am} \mathrm{Coll}$ Nutr 24, 266-274.

28. Khor GL, Duraisamy G, Loh SP et al. (2006) Dietary and blood folate status of Malaysian women of childbearing age. Asia Pac J Clin Nutr 15, 341-349.

29. Shuaibi AM, House JD \& Sevenhuysen GP (2008) Folate status of young Canadian women after folic acid fortification of grain products. J Am Diet Assoc 108, 2090-2094.

30. Buzzard M (1998) 24-Hour dietary recall and food record methods. In Nutritional Epidemiology, 2nd ed., pp. 50-73 [W Willett, editor]. New York: Oxford University Press.

31. Jacques PF, Sulsky SI, Sadowski JA et al. (1993) Comparison of micronutrient intake measured by a dietary questionnaire and biochemical indicators of micronutrient status. Am J Clin Nutr 57, 182-189.

32. Johansson I, Van Guelpen B, Hultdin J et al. (2010) Validity of food frequency questionnaire estimated intakes of folate and other $B$ vitamins in a region without folic acid fortification. Eur J Clin Nutr 64, 905-913.

33. Kondo A, Kimura K, Isobe Y et al. (2003) Folic acid reduces risks of having fetus affected with neural tube defects: dietary food folate and plasma folate concentration. Nippon Hinyokika Gakkai Zasshi 94, 551-559. 
34. van de Rest O, Durga J, Verhoef P et al. (2007) Validation of a food frequency questionnaire to assess folate intake of Dutch elderly people. Br J Nutr 98, 1014-1020.

35. Verkleij-Hagoort AC, de Vries JH, Stegers MP et al. (2007) Validation of the assessment of folate and vitamin $B_{12}$ intake in women of reproductive age: the method of triads. Eur J Clin Nutr 61, 610-615.

36. Wiltshire E, Thomas DW, Baghurst P et al. (2001) Reduced total plasma homocyst(e)ine in children and adolescents with type 1 diabetes. J Pediatr 138, 888-893.

37. Yen J, Zoumas-Morse C, Pakiz B et al. (2003) Folate intake assessment: validation of a new approach. J Am Diet Assoc 103, 991-1000.

38. Yoshino K, Nishide M, Sankai T et al. (2010) Validity of brief food frequency questionnaire for estimation of dietary intakes of folate, vitamins $\mathrm{B}_{6}$ and $\mathrm{B}_{12}$, and their associations with plasma homocysteine concentrations. Int J Food Sci Nutr 61, 61-67.

39. Jones J, Mosher W \& Daniels K (2012) Current contraceptive use in the United States, 2006-2010, and changes in patterns of use since 1995. Natl Health Stat Report 60, 1-26.

40. United Nations (2012) World contraceptive use 2011. http:// www.un.org/esa/population/publications/contraceptive 2011/wallchart_front.pdf (accessed September 2012).

41. Hou MY, Hurwitz S, Kavanagh E et al. (2010) Using daily text-message reminders to improve adherence with oral contraceptives: a randomized controlled trial. Obstet Gynecol 116, 633-640.

42. Huber LR, Hogue CJ, Stein AD et al. (2006) Contraceptive use and discontinuation: findings from the contraceptive history, initiation, and choice study. Am J Obstet Gynecol 194, 1290-1295.

43. Rosenberg MJ \& Waugh MS (1998) Oral contraceptive discontinuation: a prospective evaluation of frequency and reasons. Am J Obstet Gynecol 179, 577-582.

44. Cronin M, Schellschmidt I \& Dinger J (2009) Rate of pregnancy after using drospirenone and other progestincontaining oral contraceptives. Obstet Gynecol 114, 616-622.

45. von Stenglin A, Buchwald S \& Lynen R (2010) Women's awareness and use of folate supplements prior to and during pregnancy: a global perspective (abstract and poster presentation). Eur J Contracept Reprod Health Care 15, Suppl. 1, 111-112.

46. Diefenbach K, Trummer D, Ebert F et al. (2010) Changes in folate levels following cessation of Yasmin and levomefolate calcium $0.451 \mathrm{mg}$ or folic acid $400 \mathrm{mcg}$ co-administration. Eur J Contracept Reprod Health Care 15, 157-158.

47. Bart S, Marr J, Diefenbach K et al. (2012) Folate status and homocysteine levels during a 24-week oral administration of a folate-containing oral contraceptive: a randomized, double-blind, active-controlled, parallel-group, US-based multicenter study. Contraception 85, 42-50.

48. Pietrzik K, Bailey L \& Shane B (2010) Folic acid and L-5-methyltetrahydrofolate: comparison of clinical pharmacokinetics and pharmacodynamics. Clin Pharmacokinet 49, 535-548.

49. Lamers Y, Prinz-Langenohl R, Bramswig S et al. (2006) Red blood cell folate concentrations increase more after supplementation with [6S]-5-methyltetrahydrofolate than with folic acid in women of childbearing age. Am J Clin Nutr 84, 156-161.

50. Pietrzik K, Lamers Y, Bramswig S et al. (2007) Calculation of red blood cell folate steady state conditions and elimination kinetics after daily supplementation with various folate forms and doses in women of childbearing age. Am J Clin Nutr 86, 1414-1419.

51. Venn BJ, Green TJ, Moser R et al. (2002) Increases in blood folate indices are similar in women of childbearing age supplemented with $[6 S]-5$-methyltetrahydrofolate and folic acid. J Nutr 132, 3353-3355.

52. Rimm EB, Giovannucci EL, Stampfer MJ et al. (1992) Reproducibility and validity of an expanded self-administered semiquantitative food frequency questionnaire among male health professionals. Am J Epidemiol 135, 1114-1126.

53. Castaño PM \& Westhoff C (2006) A new tool for assessing the folate status of reproductive-aged urban Latina women. Obstet Gynecol 107, Suppl. 4, 44S-45S.

54. US Department of Agriculture (2009) National Nutrient Database for Standard Reference, Release 21. http://www. ars.usda.gov/Services/docs.htm?docid $=18880 \quad$ (accessed January 2009).

55. Castano PM, Bynum JY, Andres R et al. (2012) Effect of daily text messages on oral contraceptive continuation: a randomized controlled trial. Obstet Gynecol 119, 14-20.

56. O'Connell White K, Roca C \& Westhoff CL (2010) The impact of pack supply on oral contraceptive continuation: a randomised controlled trial. Contraception 82, 185-186.

57. Peipert JF, Zhao Q, Allsworth JE et al. (2011) Continuation and satisfaction of reversible contraception. Obstet Gynecol 117, 1105-1113.

58. Bailey RL, Dodd KW, Gahche JJ et al. (2010) Total folate and folic acid intake from foods and dietary supplements in the United States: 2003-2006. Am J Clin Nutr 91, 231-237.

59. Rader JI, Weaver CM \& Angyal G (2000) Total folate in enriched cereal-grain products in the United States following fortification. Food Chem 70, 275-289.

60. Rofail D, Colligs A, Abetz L et al. (2012) Factors contributing to the success of folic acid public health campaigns. J Public Health 34, 90-99. 